Foss. Rec., 21, 301-310, 2018

https://doi.org/10.5194/fr-21-301-2018

(C) Author(s) 2018. This work is distributed under

the Creative Commons Attribution 4.0 License.

\title{
The skull of the carettochelyid turtle Anosteira pulchra from the Eocene (Uintan) of Wyoming and the carotid canal system of carettochelyid turtles
}

\author{
Walter G. Joyce, Virginie S. Volpato, and Yann Rollot \\ Departement für Geowissenschaften, Universität Freiburg, Freiburg, 1700, Switzerland \\ Correspondence: Walter G. Joyce (walter.joyce@unifr.ch) \\ Received: 10 October 2018 - Revised: 4 December 2018 - Accepted: 4 December 2018 - Published: 13 December 2018
}

\begin{abstract}
Here we document the morphology of the only known skull of a carettochelyid turtle from North America. The specimen originates from the middle Eocene (early Uintan) Washakie Formation of Sweetwater County, Wyoming, and is referred to Anosteira pulchra based on temporal considerations. The skull of Anosteira pulchra broadly corresponds in its morphology to that of other carettochelyids but exhibits numerous differences that are related to it being more gracile. As a meaningful outgroup is lacking, it is not possible to determine if the gracile morphology seen in this taxon is apomorphic or plesiomorphic for the AnosteiraAllaeochelys clade. Anosteira pulchra and Carettochelys insculpta lack an ossified palatine canal. We conclude by reference to extant trionychids that the palatine (mandibular) canal is likely present but branches from the cerebral (pseudopalatine) canal following its exit from the sella turcica. As in trionychids, the vidian branch of the facial nerve (VII) of Anosteira pulchra and Carettochelys insculpta mostly traverses the palatine.
\end{abstract}

\section{Introduction}

The pig-nosed turtle Carettochelys insculpta Ramsay, 1887 from New Guinea and Australia is the only surviving representative of the clade Carettochelyidae (Pan-Carettochelys of Joyce et al., 2004). Highly fragmentary remains document the early evolution of this clade during the Cretaceous in Asia, but sometimes exceptionally rich material attests to the spreading of carettochelyids to all northern continents during the Paleogene. The Neogene record is restricted to exception- ally rare finds from Europe, northern Africa, south Asia, and Australia (Joyce, 2014).

The majority of carettochelyid fossil finds are shell fragments (Joyce, 2014), which can be diagnostic by their highly distinct surface texture (e.g., Hutchison, 1996). Cranial remains have been reported from the Late Cretaceous of Uzbekistan (Nessov, 1977a, b, c), the Eocene of China (Danilov et al., 2017), England (Lydekker, 1889), France (Godinot et al., 2018), Germany (Harrassowitz, 1922; Joyce et al., 2012), and Spain (Joyce, 2014), and the Miocene of Libya (Havlik et al., 2014), but only a few specimens have been properly figured and described.

A mid-20th century expedition of the Field Museum of Natural History (FMNH) to the Washakie Basin of Sweetwater County, Wyoming, yielded an isolated pan-carettochelyid skull from the middle Eocene (early Uintan North American land mammal "age", NALMA) Adobe Town Member (Twka2 or Twka3) of the Washakie Formation. Gaffney (1979, fig. 173) provided a reconstruction of this fossil (FMNH PR966) under the name "Anosteira" or "Pseudanosteira", whereas Havlik et al. (2014) used it to score all cranial aspects of the taxon "Anosteira pulchra", but a formal description is still missing. Given that FMNH PR966 is the only known pan-carettochelyid skull from North America, the primary purpose of this contribution is to provide a description of this fossil.

\section{Methods}

We subjected FMNH PR966 to high-resolution X-ray microcomputed tomography (CT) using a Bruker SkyScan 2211 at the University of Fribourg, Switzerland, with an exposure 
time of $37 \mathrm{~ms}$, a voltage of $190 \mathrm{kV}$, a current of $50 \mathrm{~mA}$, and no filter. The 1800 projections that were acquired over $360^{\circ}$ were converted into 1160 coronal slices with a voxel size of $23 \mu \mathrm{m}$ using the native software of the machine. The slice stack is available upon request at FMNH.

For comparative purposes, we obtained the CT scans of BMNH (Natural History Museum London) 1903.7.10.1, a skeleton of the extant Carettochelys insculpta, which had been acquired by Serjoscha Evers using the in-house scanner with an exposure time of $500 \mathrm{~ms}$, a voltage of $180 \mathrm{kV}$, a current of $190 \mathrm{~mA}$, and a copper filter. The 3142 projections over $360^{\circ}$ were converted into 1935 coronal sections. This dataset will be made available to the public in a separate publication that is currently in preparation.

Where possible, the basisphenoid, the right pterygoid, the carotid canals, the canalis cavernosus, and the facial nerve canals were visualized for Anosteira pulchra and C. insculpta using the software Amira (6.1.1). All reconstructions were obtained by segmentation followed by production of isosurface models. The boundaries of the bones and canals were delimited manually using the brush and lasso tools of Amira in every second to fifth slice, depending on the complexity of the contact. The remaining slices were then interpolated. The resulting 3-D models are available upon request at FMNH.

As few formal descriptions of fossil carettochelyids are available, here we compare FMNH PR966 mostly to Anosteira maomingensis (as described by Danilov et al., 2017) and Allaeochelys spp. (as described by Havlik et al., 2014, and Godinot et al., 2018).

To investigate the phylogenetic placement of Anosteira pulchra, we updated the phylogenetic analysis of Danilov et al. (2017), which in return is based on Joyce (2007) and Havlik et al. (2014). We accepted all changes that Danilov et al. (2017) made to the matrix of Havlik et al. (2014), with the exception of the following updates: (1) A. pulchra was scored 1 not ? for character 148 (see Sect. 4); (2) A. pulchra was scored 0 not ? for character 149 (see Sect. 4); (3) Allaeochelys libyca was scored ? not 0 for character 149 , as we find the relevant specimens not to be preserved sufficiently to allow scoring; finally, (4) character 150 (distance of the foramen posterius canalis carotici interni from the basisphenoid) was removed from the matrix, as we could not replicate the scoring among derived carettochelyids because most extant taxa were incorrectly scored as inapplicable, and because it appears to be correlated with character 148 (presence of a pterygoid-pterygoid suture flooring the foramen posterius canalis carotici interni). The revised matrix is available in the Supplement.

The data matrix was subjected to a parsimony analysis using TNT (Goloboff et al., 2008). Following Havlik et al. (2014), characters 7, 27, 33, 35, 54, 60, 61, 65, 68, 71, $85,89,98,120,133,134$, and 142 were run ordered. Following Havlik et al. (2014), we also restricted the ingroup to carettochelyids and utilized Adocus sp. as the outgroup. The matrix was subjected to 1000 replicates of random addi- tion sequences followed by a second round of tree bisectionreconnection. The analysis was also performed using the same parameters using implied weights with $k$ values ranging from 1 to 12 at full integers.

\section{Systematic paleontology}

Carettochelyidae Gill, 1889

Anosteira Leidy, 1871

Anosteira pulchra (Clarke, 1932)

\section{Type specimen}

Carnegie Museum 11808, an almost complete shell (Clark, 1932, figs. 1, 2).

\section{Type locality and stratum}

Near Ouray, Uinta County, Utah, USA; Uinta Formation, Uintan North American land mammal age (NALMA), middle Eocene.

\section{Material}

FMNH PR966, a near-complete but lightly crushed cranium lacking the premaxillae, the right postorbital, most of the quadratojugals, the articular process of the left quadrate, the posterior aspects of both squamosals, and the posterior aspect of the supraoccipital (Fig. 1). The find is not accompanied by shell remains or any other fauna.

\section{Locality}

Sweetwater County, Washakie Basin, Wyoming, USA; middle Eocene, early Uintan NALMA, Adobe Town Member, Twka2 or Twka3, Washakie Formation.

\section{Comments}

See Sect. 5 below for referral of FMNH PR966 to Anosteira pulchra.

\section{Description}

\section{Cranium}

The preserved midline length of FMNH PR966 is only $38 \mathrm{~mm}$ and, by comparison to Carettochelys insculpta, we estimate the original midline length to have been only a few millimeters more (Fig. 1). The skull is generally well preserved, but much dorsoventral crushing resulted in many cracks and significant distortion. The CT imagery furthermore highlights areas fully replaced by glue. The skull was likely buried completely prior to fossilization, but the premaxillae, the right postorbital, much of the quadratojugals, 

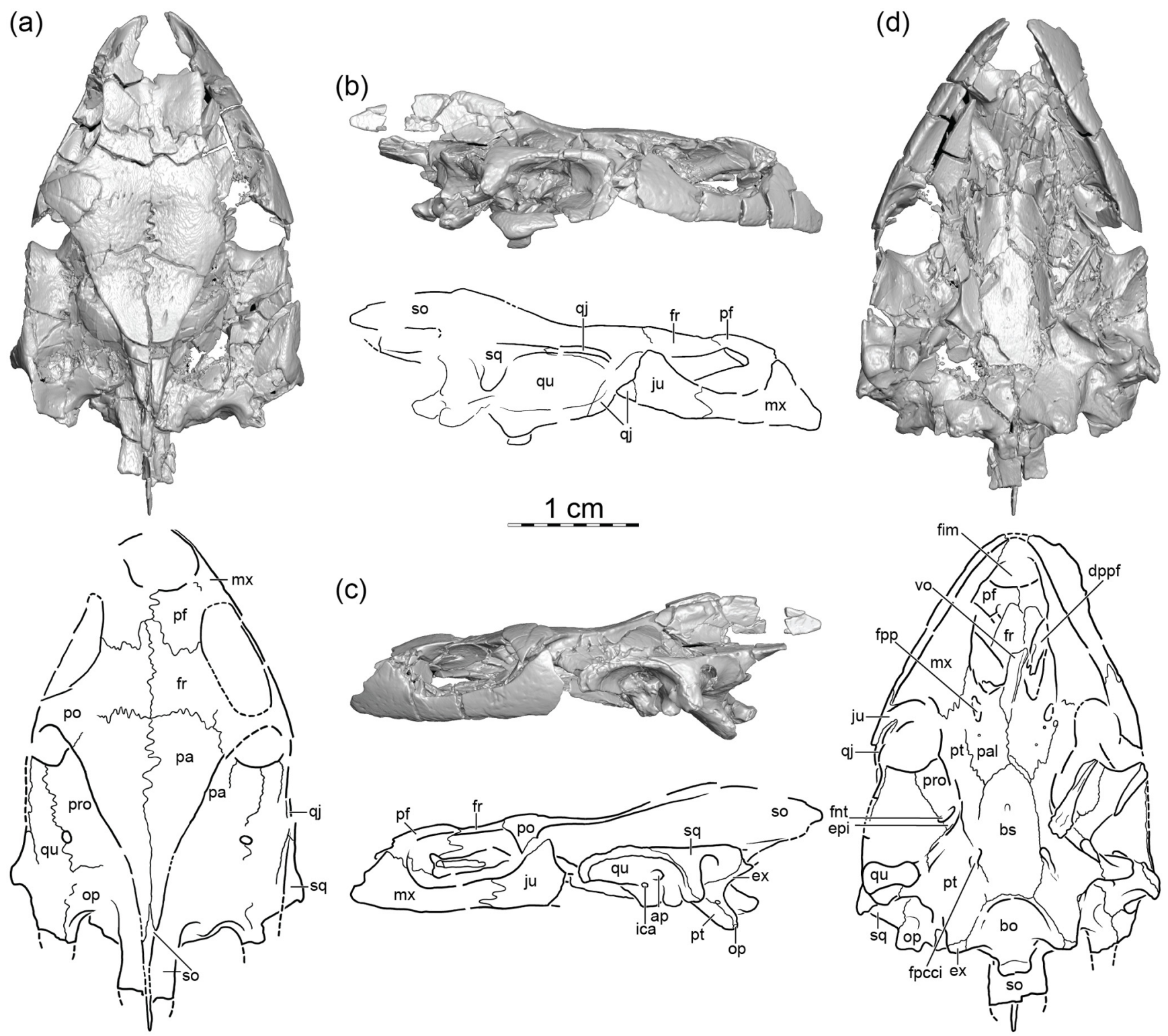

Figure 1. FMNH PR966, Anosteira pulchra, skull, middle Eocene Washakie Formation, Sweetwater County, Wyoming, USA. A 3-D rendered model and illustrations in (a) dorsal, (b) right lateral, (c) left lateral, and (d) ventral views. Abbreviations are as follows: ap: antrum postoticum; bo: basioccipital; bs: basisphenoid; dppf: descending process of the prefrontal; epi: epipterygoid; ex: exoccipital; fim: foramen intermaxillare; fnt: foramen nervi trigemini; fpcci: foramen posterius canalis carotici interni; fpp: foramen palatinum posterius; fr: frontal; ica: incisura columella auris; ju: jugal; mx: maxilla; op: opisthotic; pa: parietal; pal: palatine; pf: prefrontal; po: postorbital; pro: prootic; pt: pterygoid; qj: quadratojugal; qu: quadrate; so: supraoccipital; sq: squamosal; vo: vomer.

the articular process of the left quadrate, the posterior aspects of both squamosals, and the posterior aspect of the supraoccipital were lost post burial, likely during recovery. The dorsal skull roof shows fine texturing that resembled hammered metal. This stands in stark contrast to the shell sculpturing of Anosteira spp., which consists of fine raised ridges and nobs (Hay, 1908). The skull of FMNH PR966 is much narrower and lower than other carettochelyids, even when crushing is taken into account.

\section{Prefrontals}

The prefrontals are relatively large bones that contact the maxillae laterally, the frontals posteriorly, and one another medially. The well-developed anterior process of the frontals partially separates the prefrontals along the midline in both views (contra Gaffney, 1979). The descending process of the prefrontals is missing on the right side, but the strutlike left descending process clearly documents a ventral con- 
tact with the palatal bones, much as in $C$. insculpta, but the exact contacts are unclear. The anterior margins of the prefrontals are intact and reveal that the external nares were oriented anterodorsally. The interorbital bar formed by the prefrontals and frontals is furthermore relatively narrow and the orbits therefore face somewhat dorsolaterally. These observations contrast the morphology of Anosteira maomingensis, Allaeochelys spp., and C. insculpta, which have anteriorly oriented external nares, laterally oriented orbits, and a broad interorbital bar.

\section{Frontals}

The frontals are large elements that contact the prefrontals anteriorly, the parietals posteriorly, and the postorbitals posterolaterally, and they broadly contribute to the dorsal margin of the orbit. The frontals combined form a strong anterior process that substantially reduces the midline contact of the prefrontals in both dorsal and ventral view. The ventral aspect of this process is decorated by a ridge, which delimits the sulcus olfactorius.

\section{Parietals}

The parietals are the largest skull roofing elements and contact the frontals anteriorly, the postorbitals anterolaterally, and one another on the dorsal surface. A lateral contact with the jugals or quadratojugals appears to be absent, as in $C$. insculpta. The descending process of the parietals appears to have been relatively short. Although cracks make it difficult to interpret the contribution of the parietals to the upper temporal fossa, it appears clear that the parietals contacted the prootics anterolaterally and the opisthotics posterolaterally but did not contribute to the foramen stapedio-temporale. Crushing and matrix obscure any potential ventral contacts of the parietals in the trigeminal region. It similarly is unclear if the trigeminal foramen is split.

\section{Postorbitals}

The right postorbital is missing, but the left postorbital appears to be complete, though slightly displaced. The postorbitals contact the frontals anteromedially, the parietals posteromedially, and the jugals ventrolaterally, and they contribute to the orbital margin anteriorly and the upper temporal emargination posteriorly. The postorbital bar is much narrower than in $C$. insculpta and the jugals therefore appear to contribute to the upper temporal emargination. The postorbitals, conversely, are anteroposteriorly short and do not contact the quadratojugals, which both contrast the condition seen in An. maomingensis, Allaeochelys spp., and C. insculpta.

\section{Jugals}

Some of the most notable differences from other carettochelyids are apparent in the jugals of FMNH PR966. The jugals contribute to the temporal bar, which must have been much lower dorsoventrally than reconstructed by Gaffney (1979), even when crushing is taken into account. The jugals otherwise contact the postorbitals medially, possibly contribute to the upper temporal emargination posteriorly, contact the quadratojugals posteriorly, contribute to the nuanced lower temporal emargination ventrally, contact the maxillae below the orbit, and broadly floor the posterior aspects of the orbit. In Allaeochelys spp. and C. insculpta, by contrast, the quadratojugals have well-developed anterior processes that block the jugals from contributing to the upper and lower temporal emarginations.

\section{Quadratojugals}

The left quadratojugal appears to be missing completely, but three fragments of the right quadratojugal remain that combined allow the deduction of much of the morphology of this element. The anterior fragment is visible in right lateral view. This fragment broadly underlays the jugal and is much larger than apparent from lateral view. The second fragment contacts the quadrate posteroventrally and contributes to the cavum tympani (contra Gaffney, 1979). The third fragment, finally, broadly contacts the quadrate posteroventrally and clearly contacts the squamosal posteriorly (contra Gaffney, 1979). It is unclear if a contact was present with the postorbital. The most notable difference from Allaeochelys spp. and C. insculpta is the lacking anterior contact of the quadratojugal with the maxilla, a feature otherwise seen in An. maomingensis.

\section{Squamosals}

Both squamosals are present, but the posterior aspects are heavily damaged. In lateral view, the squamosals frame much of the posterior rim of the cavum tympani and contact the quadratojugals anteriorly, the quadrates ventrally, and the opisthotics posteriorly. Well-defined antra postotica are apparent on both sides that are highly reduced, though somewhat larger than in An. maomingensis, Allaeochelys spp., and C. insculpta. Within the upper temporal fossa, the squamosals narrowly define the lateral margin of the skull in form of a ridge and otherwise broadly contact the quadrates and opisthotics medially. The squamosal horns are damaged on both sides of the skull and their posterior extent is therefore unclear.

\section{Premaxillae}

The premaxillae are not preserved. 


\section{Maxillae}

In contrast to An. maomingensis, Allaeochelys spp., and C. insculpta, the maxillae are notably low in lateral view, which supports the notion that the skull of FMNH PR966 was relatively low, even prior to crushing. In lateral view, the maxillae form the anteroventral margin of the orbit, contact the prefrontals dorsally, the jugals posteriorly, the premaxillae likely anteromedially, and broadly floor the anterior aspects of the orbit. In ventral view, the maxillae form the low but blunt labial ridge, form a modestly broad and flat triturating surface, medially contact the palatines, and posteriorly contact the jugals and pterygoids. The maxillae finally frame a large foramen intermaxillaris. A posterior contact with the quadratojugals is missing.

\section{Vomer}

As in all trionychians, the vomer is a highly reduced, rod-like bone with a low ventral ridge. It lacks an anterior contact with the premaxillae and thereby helps to create the large foramen intermaxillaris. The vomer otherwise contacts the strut-like descending process of the prefrontals anterolaterally and the palatines posterolaterally.

\section{Palatines}

The palatines are large elements that roof much of the primary palate. They contact the vomer and the strut-like descending process of the prefrontal anteriorly, the maxillae and pterygoids laterally, and the basisphenoid posteriorly. The palatines form small foramina palatinum posterius near the lateral contact of the palatines with the pterygoids. Crushing and matrix obscure the ascending processes of the palatines.

\section{Pterygoids}

The pterygoids are anteroposteriorly elongate elements that broadly brace the braincase. The anterior plate delimits the lateral margins of the broad nasal canal and contacts the maxillae anteriorly and the palatines and basisphenoid medially. The mandibular process contacts the quadrates posterolaterally but does not reach the articular condyles. The broad posterior process broadly contacts the basisphenoid medially, the basioccipital posteromedially, the quadrates and opisthotics laterally, the exoccipital posteriorly, forms the margin of the reduced fenestra postotica, and contributes to the tubera basioccipitalis, a broad set of morphological characteristics seen in other carettochelyids. However, in contrast to An. maomingensis, Allaeochelys spp., and C. insculpta, a deep, triangular pterygoid fossa is lacking and the foramen posterius canalis carotici interni is not located within the pterygoid, but rather at the contact with the basisphenoid, somewhat reminiscent of the condition seen in paracryptodires.

\section{Epipterygoids}

The epipterygoids are preserved on both sides of the skull but partially obscured by crushing and matrix. From what can be seen, it appears that the epipterygoids are anteroposteriorly elongate elements that contact the prootic posteriorly and the pterygoid ventrally and frame the posterior portion of the trigeminal foramen dorsally. The anterior aspects of this bone are unclear.

\section{Quadrate}

The quadrates are both relatively well preserved, but various parts are missing or somewhat obscured by crushing. In lateral view, the quadrates form the majority of the cavum tympani and contact the quadratojugals anteriorly and the squamosals posterodorsally, but they do not contribute to the margin of the upper temporal emargination. The articular condyle is notably low, the incisura columella auris fully enclosed, and the anterior rim of the highly reduced antrum postoticum is fully defined by the quadrate, much as in other carettochelyids.

In ventral view the quadrates broadly contact the prootics and pterygoids medially and the quadratojugals anterolaterally within the lower temporal fossa. Posterior to the articular process, the quadrates furthermore contact the squamosals posteriorly and the opisthotics posteromedially and frame the lateral margin of the fenestra postotica. The quadrates are broadly exposed in dorsal view within the upper temporal fossa where they contact the prootics anteromedially and the opisthotics posteromedially and are narrowly covered by the squamosals dorsolaterally. The foramen stapediotemporale is situated above the ear region at the suture between the quadrate and prootic. The quadrates form the processus trochlearis oticum together with the prootics, but only the quadrate portion of that structure is decorated by fine crenulations reminiscent of a cartilaginous cap. Like other basal branching carettochelyids, the quadrates possess a modest fossa at the base of the articular process, in contrast to the deep cavities found in Allaeochelys spp. and $C$. insculpta.

\section{Prootic}

Within the upper temporal fossa, the prootics contact the quadrates laterally, the parietals medially, and the opisthotics posteriorly and form the medial margin of the foramen stapedio-temporale and the medial portions of the low processus trochlearis oticum. A low protrusion that is formed by the prootics and parietals defines the lateral aspect of the processus trochlearis oticum. Within the lower temporal fossa, the prootics contact the quadrates laterally, but the medial aspects are obscured by matrix and crushing. It nevertheless seems apparent that the prootics subdivide the foramen nervi 
trigemini into two distinct foramina, much as in other carettochelyids.

\section{Opisthotic}

The opisthotics are broadly exposed in dorsal view within the upper temporal fossa. They contact the prootics anteriorly, the quadrates and squamosals laterally, and the supraoccipital medially. In ventral view, the opisthotics contact the quadrates anterolaterally, the squamosals posterolaterally, and the pterygoids and exoccipitals medially, form the lateral margin of the reduced fenestra postotica, and support the base of the short tubera basioccipitalis.

\section{Supraoccipital}

The contacts of the supraoccipital within the upper temporal fossa are partially obscured by cracks, but it is clear that this bone contacts the prootics and opisthotics above the otic capsule, the parietals anterodorsally, and the exoccipitals ventrolaterally, as in most turtles. The supraoccipital otherwise forms the majority of the crista supraoccipitalis, which is notably T-shaped in cross section, as in other carettochelyids. The horizontal portion of the crista is damaged at its posterior end, but the vertical portion is intact. By comparison to $C$. insculpta we therefore conclude that the full length of the crista is likely preserved and that the horizontal plate is notably narrower than in C. insculpta.

\section{Exoccipital}

In posterior view, the exoccipitals form the lateral margins of the foramen magnum, contact the supraoccipital dorsally and the basioccipital ventrally, contribute to the occipital condyle and the tubera basioccipitalis, and form two pairs of foramina nervi hypoglossi. A broad contact between the opisthotic dorsally and the pterygoid and exoccipital ventrally fully separates the small fenestra postotica from the enclosed posterior jugular foramen, which is located between the exoccipital and the opisthotic.

\section{Basioccipital}

In ventral view, the basioccipital contacts the basisphenoid anteriorly and the pterygoids laterally and contributes to the formation of the occipital condyle and the tubera basioccipitalis. A broad semicircular depression is apparent on the basioccipital in ventral view that is fully restricted to this bone.

\section{Basisphenoid}

The basisphenoid is an elongate element that broadly contacts the pterygoids laterally and the basioccipital posteriorly. The basisphenoid apparently forms a thin sheet of bone, perhaps the homolog of the parasphenoid (Sterli et al., 2010), that partially underlaps the basioccipital, but much of this sheet of bone is now lacking on the right side. The foramen posterius canalis carotici interni is unusual by being situated at the contact of the basisphenoid with the pterygoid. A small knob with uncertain function or homology finally adorns the midline of the basisphenoid. Such a knob has not been reported for other carettochelyids.

\section{Carotid canals}

A diagonal grove is present on the ventral side of the pterygoids that leads to a relatively large foramen located halfway along the contact of the basisphenoid and pterygoid. CT images indicate that the foramen is the posterior opening of a canal that penetrates the basisphenoid anteromedially and that opens close to its counterpoint within the sella turcica (Fig. 2). A small canal branches from the large canal halfway along its path through the basisphenoid. The second canal mostly penetrates the palatines (Fig. 2). These canals can be found in the extant $C$. insculpta as well, with the notable difference that the large canal penetrates the pterygoids further towards the back (Fig. 3). We identify the small canal in both animals by reference to the known canals in trionychids (Albrecht, 1967) as the canalis nervus vidianus and the large canal as the canalis caroticus internus (sensu Rabi et al., 2013) prior to its split into the cerebral and palatal branches. Our full rationale for these identifications is explained below (see Sect. 5). The primary difference between the fossil Anosteira pulchra and the extant Carettochelys insculpta is the relative placement of the foramen posterius canalis carotici interni. The foramen is located halfway along the contact of the basisphenoid and pterygoid in A. pulchra. This superficially resembles the condition seen in paracryptodires (Gaffney, 1975). The same foramen is typically positioned further to the back in $C$. insculpta within the pterygoid, although much variation is apparent among figured material with some specimens displaying a condition that resembles A. pulchra (e.g., Waite, 1905; Joyce, 2014; Godinot et al., 2018). The pterygoid furthermore forms a suture with itself along the floor it forms of the canalis caroticus internus. To our knowledge, this suture is unique among turtles.

\section{Facial nerve canals}

A thick, laterally oriented canal connects the fossa acusticofacialis in C. insculpta with the short, enclosed portion of the sulcus cavernosus. A small, poorly traceable canal branches from the large canal. This small canal leads from the large canal to the ventral surface of the skull near the foramen posterius canalis carotici interni (Fig. 3). The skull of A. pulchra is badly crushed in the relevant region, but the canals apparent in C. insculpta appear to be present here as well, but are too fragmentary to allow visualizing in 3-D. We identify the smaller canal as the canalis pro ramo nervi vidiani (sensu Rollot et al., 2018). The medial portion of the large canal is therefore the canalis nervus facialis and the lateral portion 


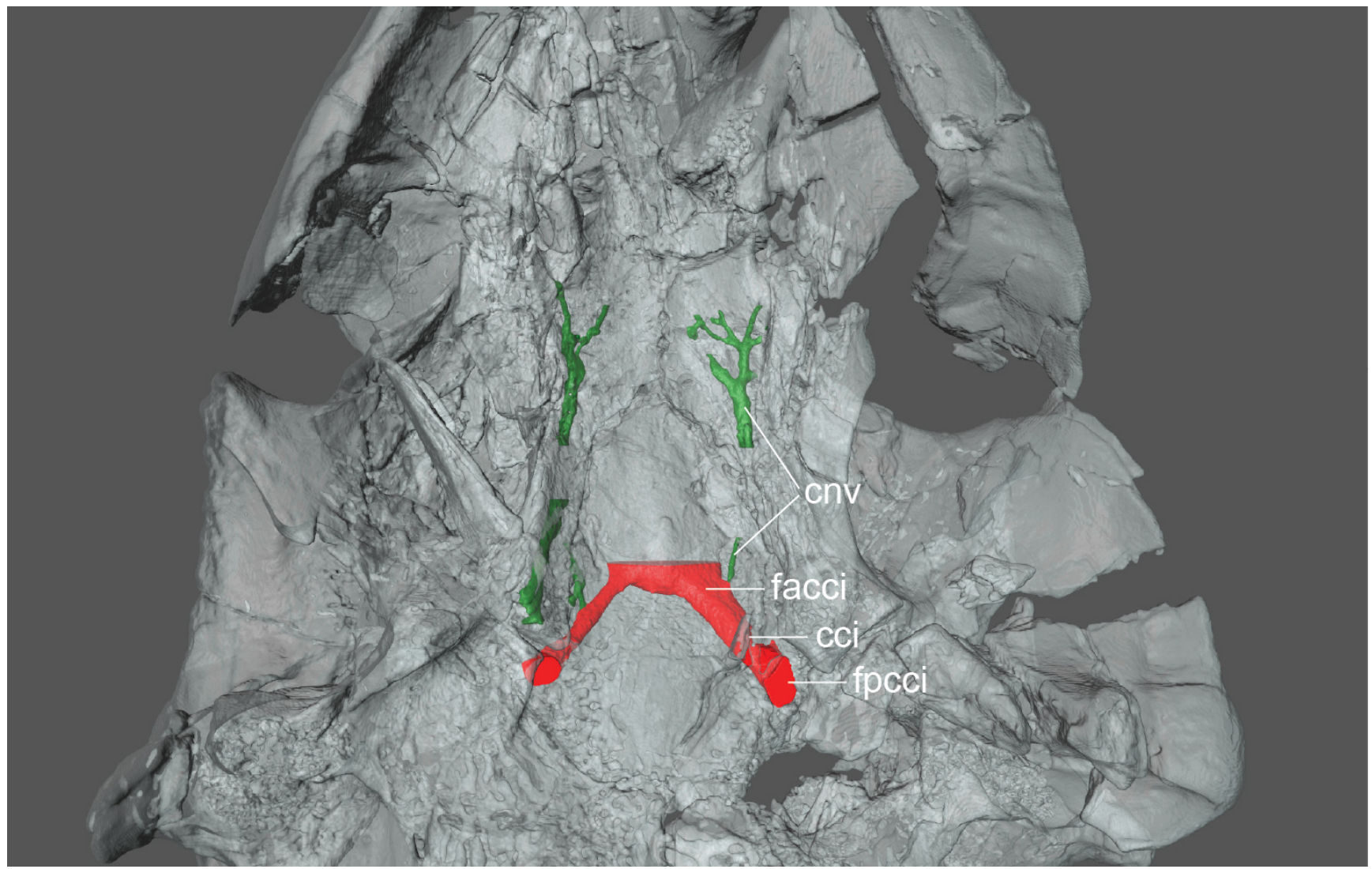

Figure 2. FMNH PR966, Anosteira pulchra, skull, middle Eocene Washakie Formation, Sweetwater County, Wyoming, USA. A 3-D rendered model of the skull, internal carotid, and facial nerve canals in ventral view. Abbreviations are as follows: cci: canalis caroticus internus; cnv: canalis nervus vidianus; facci: foramen anterius canalis carotici interni; fpcci: foramen posterius canalis carotici interni.

the canalis pro ramo nervi hyomandibularis. Our rationale for these identifications is explained below (see Sect. 5).

\section{Discussion}

\section{Alpha taxonomy}

Two pan-carettochelyids are currently recognized as valid from the Eocene of North America: Anosteira ornata Leidy, 1871 from the early-middle Eocene (Bridgerian NALMA) of Wyoming and Anosteira pulchra (Clark, 1932) from the middle Eocene (Uintan NALMA) of Utah (Joyce, 2014). No cranial material associated directly with either taxon has yet been found. Joyce (2014) noted that it is unclear if the apparent differences between the two recognized species are due to intraspecific variation, poor preservation, or true taxonomic differences. It is therefore plausible that both taxa are synonymous or chronotaxa. As no morphological data are available that would allow referring FMNH PR966 to either taxon, Joyce (2014) identified this specimen as Anosteira indet. Havlik et al. (2014), by contrast, referred this specimen to Anosteira pulchra using temporal considerations and uti- lized it to score cranial characters for cladistic analysis. We follow this assessment herein as well.

\section{Phylogeny}

Our phylogenetic analysis retrieved 41 most parsimonious trees with 48 steps. The strict consensus replicates the results of Danilov et al. (2017, fig. 5b) by finding a paraphyletic Kizylkumemys, a fully unresolved, paraphyletic Anosteira, and a fully unresolved clade consisting of $\mathrm{Al}$ laeochelys spp. and Carettochelys insculpta. In contrast to Danilov et al. (2017), however, this analysis did not demand omitting Anosteira lingnanica to achieve this level of resolution. Utilizing implied weight with $k$ values ranging from 1 to 12 does not impact the outcome of the analysis. As our result is identical to previous results, we do not figure a tree herein.

Our description highlights consistent differences between Anosteira pulchra and all other properly described carettochelyids. The vast majority of differences pertain to the fact that the skull of Anosteira pulchra is narrower, that the orbits and external nares are oriented more laterodorsally and anterodorsally, respectively, that the postorbital bar is more 


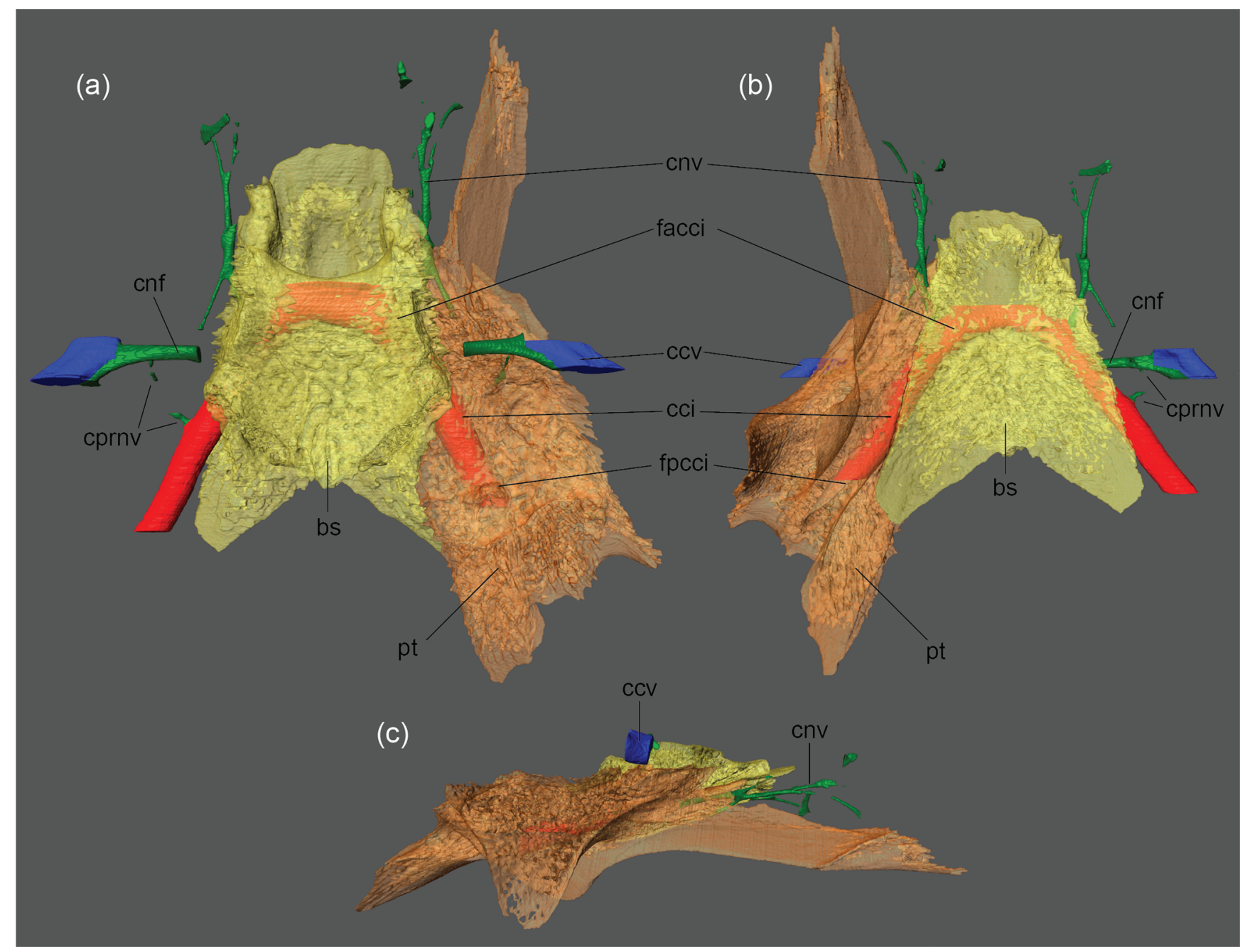

Figure 3. BMNH 1903.7.10.1, Carettochelys insculpta, skull. The 3-D rendered models of the basisphenoid, right pterygoid, internal carotid, and facial nerve canals in (a) dorsal, (b) ventral, and (c) left lateral views. Abbreviations are as follows: bs: basisphenoid; cci: canalis caroticus internus; ccv: canalis cavernosus; cnf: canalis nervus facialis; cnv: canalis nervus vidianus; cprnv: canalis pro ramo nervi vidiani; facci: foramen anterius canalis carotici interni; fpcci: foramen posterius canalis carotici interni; pt: pterygoid.

gracile, and that the jaws and triturating surfaces are narrower.

The skull of the closest unambiguous outgroup to the Anosteira-Allaeochelys clade, Kizylkumemys schultzi, is not well known (see scoring of Danilov et al., 2017, based on first-hand observation of the available material) and it is therefore not possible to correctly polarize these character complexes. The overall gracile skull of Anosteira pulchra may therefore be an apomorphic feature of this North American taxon.

\section{Cranial circulation and innervation}

To our knowledge, the cranial circulation and innervation has not yet been described for Carettochelys insculpta and we therefore identify the canals of the carettochelyids for which we have CT datasets by reference to published dissections, mostly Albrecht $(1967,1976)$.

Anosteira pulchra and Carettochelys insculpta possess an enlarged canal that diagonally penetrates the basisphenoid (Figs. 2, 3). The canal originates near the pterygoidbasisphenoid suture in An. pulchra, but further posterior, within the pterygoid only, in $C$. insculpta. In both cases, the canal terminates within the sella turcica. In both cases, a small canal branches from the large canal, which mostly crosses the palatine and terminates in numerous diffuse foramina on the dorsal and ventral sides of the palate. These two canals are broadly consistent with the internal carotid and vidian nerve canals described by Albrecht (1967) for the trionychid Apalone spinifera (his Trionyx spinifer), the closet living relative for which data are available. The primary difference we note is that Albrecht (1967) reported 
that the internal carotid of Apalone spinifera splits into two branches, of which one exits anteromedially in the sella turcica and the other anterolaterally in the sulcus cavernosus. As the medial canal feeds the brain and the palate and the lateral canal the mandible, Albrecht (1967) named the medial canal the pseudopalatine artery and the lateral canal the mandibular artery, but we here follow Rabi et al. (2013) by naming them the cerebral and palatine arteries to emphasize their topological homology with similar canals in other turtles. The lack of a palatal canal either reflects the reduction of the palatine artery in carettochelyids, as seen for instance in some paracryptodires (Rollot et al., 2018) or may indicate that the split occurs after the internal canal exits the sella turcica. As the split occurs close to the sella turcica in Apalone spinfera, we find the second hypothesis to be more plausible, but only the dissection of a Carettochelys insculpta cranium will be able to resolve this question unambiguously. Albrecht (1976) arrived at a similar conclusion by reference to an unpublished dissection of the extant trionychid Lissemys punctata, for which the mandibular artery was reported to originate from the cerebral artery. The two carettochelyids resemble Apalone spinfera in that the vidian canal mostly traverses the palatine, in contrast to all other turtles, in which the canal traverses the pterygoid (Albrecht, 1967, 1976; Rollot et al., 2018). This arrangement may therefore serve as yet another synapomorphy for Trionychia.

A relatively thick, straight canal connects the brain cavity with the canalis cavernosus in Anosteira pulchra and Carettochelys insculpta. A second, much thinner canal that is hard to trace exits this canal, transverses the pterygoid, and surfaces within or near the canal of the internal carotid artery. The thick canal is broadly consistent with canalis nervus facialis and the small canal with the canalis pro ramo nervi vidiani (sensu Rollot et al., 2018) of other turtles (Albrecht, 1967, 1976). If the split of the facial nerve into the hyomandibular and vidian branches occurred within the thick canal, the lateral portion of the thick canal should be interpreted as the canalis pro ramo nervi hyomandibularis. However, as the location of the geniculate ganglion is unclear, it is equally likely that (1) the two nerves always split within the cavum cranii and traverse the medial part of the facial canal together, (2) the two nerves split within the facial canal, or (3) that the nerves split within the canalis cavernosus and that the vidian nerves utilizes the facial canal again on the way to the surface. Too few comparative data are available to enable us to restrict our options.

Data availability. The CT slice data and models produced for this study are available at FMNH. The character/taxon matrix is available in the Supplement.

Supplement. The supplement related to this article is available online at: https://doi.org/10.5194/fr-21-301-2018-supplement.
Author contributions. WGJ conceived the project and CT scanned the specimen. VSV and YR created preliminary and final 3-D models. All authors wrote and approved the paper.

Competing interests. The authors declare that they have no conflict of interest.

Acknowledgements. We would like to thank Bill Simpson and Olivier Rieppel (FMNH) for loaning FMNH PR966 for study at the University of Fribourg. Christoph Neururer (University of Fribourg) is acknowledged for help with CT scanning. Serjoscha Evers (University of Oxford) is thanked for providing us with access to the CT scans of BMNH 1903.7.10.1. Igor Danilov and the anonymous reviewer are thanked for insightful remarks that helped improve the quality of this paper. This study was supported by grants from the Swiss National Science Foundation to WGJ (SNF 200021_156087 and SNF 200021_178780/1).

Edited by: Torsten Scheyer

Reviewed by: Igor Danilov and one anonymous referee

\section{References}

Albrecht, P. W.: The cranial arteries and cranial arterial foramina of the turtle genera Chrysemys, Sternotherus, and Trionyx: a comparative study with analysis of possible evolutionary implications, Tulane Stud. Zool., 14, 81-99, 1967.

Albrecht, P. W.: The cranial arteries of turtles and their evolutionary significance, J. Morphol., 149, 159-182, 1976.

Clark, J.: A new anosteirid from the Uinta Eocene, An. Carn. Mus. Nat. Hist., 21, 161-170, 1932.

Danilov, I. G., Obraztsova, E. M., Chen, W., and Jin, J.: The cranial morphology of Anosteira maomingensis (Testudines, PanCarettochelys) and the evolution of pan-carettochelyid turtles, J. Vert. Paleontol., 37, e1335735, 1-13, 2017.

Gaffney, E. S.: A phylogeny and classification of the higher categories of turtles, B. Am. Mus. Nat. Hist., 155, 387-436, 1975.

Gaffney, E. S.: Comparative cranial morphology of Recent and fossil turtles, B. Am. Mus. Nat. Hist., 164, 65-376, 1979.

Gill. T.: A remarkable tortoise, in: Annual Report of the Board of Regents of the Smithsonian Institution, for the Year Ending June 30th, 1887, Pt. 1, Government Printing Office, Washington D.C., USA, 509-511, 1889.

Godinot, M., Lavarrere, H.-P., Erfurt, J., Franzen, J. L., LangeBadré, B., de Lapparent de Broin, F., and Vidalenc, D.: Un nouveau gisement à vertébrés éocènes, Rouzilhac (MP 10-11), dans la série molassique d'Issel (Aude, France), Rev. Paléobiol., 37, 141-333, 2018.

Goloboff, P. A., Farris, J. S., and Nixon, K.: TNT. A free program for phylogenetic analysis, Cladistics, 24, 774-786, 2008.

Harrassowitz, H.: Die Schildkrötengattung Anosteira von Messel bei Darmstadt und ihre stammesgeschichtliche Bedeutung, Abh. Hess. Geol. Landesanst., 6, 132-239, 1922.

Havlik, P. E., Joyce, W. G., and Böhme M.: Allaeochelys libyca, a new carettochelyine turtle from the middle Miocene of Libya, B. Peabody Mus. Nat, Hi., 55, 201-214, 2014. 
Hay, O. P. The fossil turtles of North America, Publ. Carn. Inst. Wash., 75, 1-568, 1908.

Hutchison, J. H.: Testudines, in: The Terrestrial Eocene-Oligocene Transition in North America, edited by: Prothero, D. R. and Emry, R. J., Cambridge University Press, Cambridge, UK, 337353, 1996.

Joyce, W. G.: Phylogenetic relationships of Mesozoic turtles, B. Peabody Mus. Nat, Hi., 48, 3-102, 2007.

Joyce, W. G.: A review of the fossil record of turtles of the clade Pan-Carettochelys, B. Peabody Mus. Nat, Hi., 55, 3-33, 2014.

Joyce, W. G., Parham J. F., and Gauthier, J. A.: Developing a protocol for the conversion of rank-based taxon names to phylogenetically defined clade names, as exemplified by turtles, J. Paleontol., 78, 989-1013, 2004.

Joyce, W. G., Micklich, N., Schaal, S. F. K., and Scheyer T. M.: Caught in the act: the first record of copulating fossil vertebrates, Biol. Letters, 8, 846-848, 2012.

Leidy, J.: Remarks on some extinct turtles from Wyoming Territory, P. Acad. Nat. Sci. Phila., 1871, 102-103, 1871.

Lydekker, R.: On remains of Eocene and Mesozoic Chelonia and a tooth of (?) Ornithopsis, Q. J. Geol. Soc. Lond., 45, 227-246, 1889.

Nessov, L. A.: Novyy rod dvukogotnykh cherapakh iz verkhnego mela Karakalpakii, Paleontol. Zh., 10, 103-114, 1977a (in Russian).
Nessov, L. A.: A new genus of pitted-shelled turtle from the Upper Cretaceous of Karakalpakia, Paleontol. J., 10, 96-107, 1977b.

Nessov, L. A.: Concerning some features in the skull structure of two Late Cretaceous turtles, Vestn. Lenin. Univ., Ser. 3, 1977, 45-48, 1977c (in Russian with English summary).

Rabi, M., Zhou, C.-F., Wings, O., Ge, S., and Joyce, W. G.: A new xinjiangchelyid turtle from the Middle Jurassic of Xinjiang, China and the evolution of the basipterygoid process in Mesozoic turtlesm BMC Evol. Biol., 13, 1-20, 2013.

Ramsay, E. P.: On a new genus and species of freshwater tortoise from the Fly River, New Guinea, P. Linn. Soc. N. S. W., 1, 158$162,1887$.

Rollot, Y., Lyson, T. R., and Joyce, W. G.: A description of the skull of Eubaena cephalica (Hay, 1904) and new insights into the cranial circulation and innervation of baenid turtles, J. Vert. Paleontol., 38, e1474886, 1-11, 2018.

Sterli, J., Müller, J., Anquetin, J., and Hilger, A.: The parabasisphenoid complex in Mesozoic turtles and the evolution of the testudinate basicranium, Can. J. Earth Sci., 47, 1337-1346, 2010.

Waite, E. R.: The osteology of the New Guinea turtle (Carettochelys insculpta, Ramsay), Rec. Aust. Mus., 6, 110-118, 1905. 